\title{
Assessment of Prevalence and Reasons for Termination of Pregnancy at Jimma University Teaching Hospital, Ethiopia
}

\author{
Diriba Gebeyehu ${ }^{1, *}$, Bitiya Admassu' ${ }^{2}$, Makida Sinega ${ }^{2}$, Merga Haile $^{3}$ \\ ${ }^{1}$ Department of Medicine, College of health Sciences, Jimma University, Ethiopia \\ ${ }^{2}$ Department of Reproductive Health, College of health Sciences, Jimma University, Ethiopia \\ ${ }^{3}$ Department of Anesthesia, Jimma University, Ethiopia
}

Copyright (C) 2015 by authors, all rights reserved. Authors agree that this article remains permanently open access under the terms of the Creative Commons Attribution License 4.0 International License

\begin{abstract}
Background: Increasing legal access to abortion is associated with improvement in sexual and reproductive health. Conversely, unsafe abortion and related mortality are both highest in countries with narrow grounds for legal abortion. The objective of this study was to determine the prevalence and reasons for terminations of pregnancy at Jimma university teaching hospital. Methods: A retrospective cross sectional study was conducted at JUTH from June15-28, 2015, a total of 194 cards of women who came for abortion services from January 2012-January 2014 were included by systematic random sampling with inclusion and exclusion criteria. Chi square (x2) test calculated to analyze the statistical association between abortion types and other variables, $p$-value less than 0.05 was considered statistically significant. Result: According to this study, of the total calculated 194 sample size from clients admitted for both spontaneous and induced abortion $125(64.4 \%)$ were spontaneous and 69(35.6\%) were induced abortion. 28(14.4\%) of incomplete spontaneous abortion occurs between age of 25-years.one of the most common complication in this study was sepsis $23(11.9 \%)$. This study revealed that the main reason for induced abortion was due to rape and economic problem which holds $30(15.5 \%)$ and $16(8.2 \%)$ respectively Occupation and marital status are strongly associated with types of abortion with p-value of $\mathrm{P}<0.001$. Conclusion and recommendation: The study concludes that majority of abortion were spontaneous abortion which almost hold all septic abortion and majority of induced abortion were teenage, single students and most of them presented after 2nd trimester of pregnancy which increases the complication of abortion. Thus, health education on dangers of induced abortion, spontaneous abortion and utilization of contraceptive methods services to all women are highly recommended.
\end{abstract}

Keywords Spontaneous Abortion, Pregnancy, Induced Abortion, Family Planning

\section{Introduction}

The National Center for Health Statistics, the Centers for Disease Control and Prevention, and the World Health Organization define abortion as pregnancy termination prior to20 weeks' gestation or with a fetus born weighing less than $500 \mathrm{gm} 1$. In several countries, legal inquiry, prosecution, and even imprisonment of women who have had an unlawful abortion is not uncommon ${ }^{2}$

Prior to 2004; abortion was permitted in Ethiopia only to save a woman's life, protect her health and in cases of rape. According to the new penal code, adopted in 2004, abortion is not punishable when it is performed to save a woman's life or health; in cases of rape, incest or serious fetal impairment; or when a pregnant woman lacks the capacity to care for a child because of her young age or her deficient physical or mental health. Almost all abortion related death occur in developing countries; Africa (30,000), Asia (34,000), Latin America and Caribbean (4000)3. These shows unsafe abortion have been important public health problem globally, especially in developing countries other than maternal death4. In Africa, the risk of dying after unsafe abortion is one in hundred fifty. The percent of maternal deaths due to unsafe abortion is $13 \%{ }^{5}$

Worldwide, the most commonly reported reason women cite for having an abortion is to postpone or stop childbearing. The second most common reason-socioeconomic concerns - includes disruption of education or employment; lack of support from the father; desire to provide schooling for existing children; and poverty, unemployment or inability to afford additional children. Women's characteristics are associated with their reasons for having an abortion $^{6}$ Several studies in Ethiopia indicate that unsafe abortion may account for up to $25-35 \%$ of the maternal death, currently the law allows abortion in case of rape, incest and 
when women lacks capacity to care for a child because of her age, medical and mental illness of mother without any confirmatio $^{7}$. A community based study in Addis Ababa has found that unsafe abortion was the leading cause of maternal mortality ${ }^{8}$. Another study in five hospitals in Addis Ababa has also estimated that up to $50 \%$ of gynecological beds are occupied by abortion related cause ${ }^{9}$.A large proportion of these deaths are attributable to complications of abortion. It is clearly known that abortion and its complications are common in our country and studies done previously showed that there is persistently high prevalence of abortion related maternal deaths yet no safe solution is traced to the problem. Thus, this study figures out types, prevalence and reason out why Women seek to terminate pregnancy in JUTH, which could provide relevant information to improve and guide health care.

\section{Methodology}

\subsection{Study Design and Setting}

The study was conducted at Jimma University Teaching hospital which is found in Jimma town located $343 \mathrm{~km}$ from the country capital city. JUTH was established in 1930 and currently gives health services in seven departments(obstetrics and gynecology, pediatrics and child health, Internal Medicine, Surgery, Ophthalmology, Dermatology and Psychiatry).Obstetrics and gynecology department has 3 wards(gynecology, maternity and Labor).Each has 35,40 and 6 beds respectively for admission. The hospital also give services like safe abortion care, post-abortion care, family planning, ANC follow up health education and trainings for health professionals. Using retrospective cross sectional study from June15-28, 2015 with systematic random sampling a total of 194 cards of women who came for abortion services and admitted to Jimma University gynecologic ward from January 2012 G.C to January 2014 G.C were included by using inclusion and exclusion criteria. Sociodemographic characteristics of the respondents, types of abortions, type of contraceptive used after abortion done, types of procedure, reason for termination of pregnancy for safe abortion, family planning used after abortion were obtained from patient records using check list and the collected data was checked at the end of each day for their completeness, and consistency, and it was cleaned manually and analyzed using SPSS version 16.0. Chi square $\left(\mathrm{x}^{2}\right)$ test calculated to analyze the statistical association between types of abortions and other variables, P-value less than 0.05 was considered statistically significant. Terminated pregnancy for GTD and Ectopic pregnancy were excluded from the study.

\section{Sample size determination and sampling techniques}

Records review of the patient's card was conducted on patient who was seen at JUSH, gynecology ward and underwent abortion from January 2012-January2014.

Sample size was determined by single population proportion formula and Systematic sampling technique was employed to select patient's cards. After arranging according to the dates of admission every $5^{\text {th }}$ card was selected and included in the study

$\mathrm{N}=$ minimum sample size required

$\mathrm{Z}=$ the standard normal variance $(1.96)$

$\mathrm{P}=0.19$ (according to research done in North West Ethiopia) [15]

$\mathrm{q}=1-\mathrm{p}=1-0.19=0.81$

$\mathrm{D}=$ margin of error $=0.05$

$\mathrm{N}=\mathrm{Z} 2 \mathrm{p}(1-\mathrm{p}) / \mathrm{d} 2=237$

Where $\mathrm{N}<10,000$ sample size adjusted by

$\mathrm{Nf}=\mathrm{n} / 1+\mathrm{n} / \mathrm{N}$ where $\mathrm{n}=$ the minimum sample size $=237$

Final corrected sample size $=194$

\section{Ethical consideration}

Before the actual data collection process, an official permission letter was obtained from Ethical committee of Jimma University; in addition the brief explanation of the study objective was given for record keeper workers about the objective of this study and confidentiality of patients' information.

\section{Operational definitions}

Abortion rate: Number of abortions per 1000 females 15-44 years old.

Abortion ratio: Number of abortion per 1,000 live births

Abortion: termination of pregnancy before the fetus is capable of extra uterine life (Before 28 weeks of GA in Ethiopia).

Induced abortion: Abortion caused by deliberate interference

Maternal mortality: The number of maternal death per 100,000 live births

Safe abortion: When abortion is done in an environment which fulfills the minimum medical standard and by skilled care provider.

Spontaneous abortion: Termination of pregnancy which is not provoked.

Teenage: children aged between thirteen and nineteen years old.

Unsafe abortion: Termination of pregnancy performed or treated by untrained person.

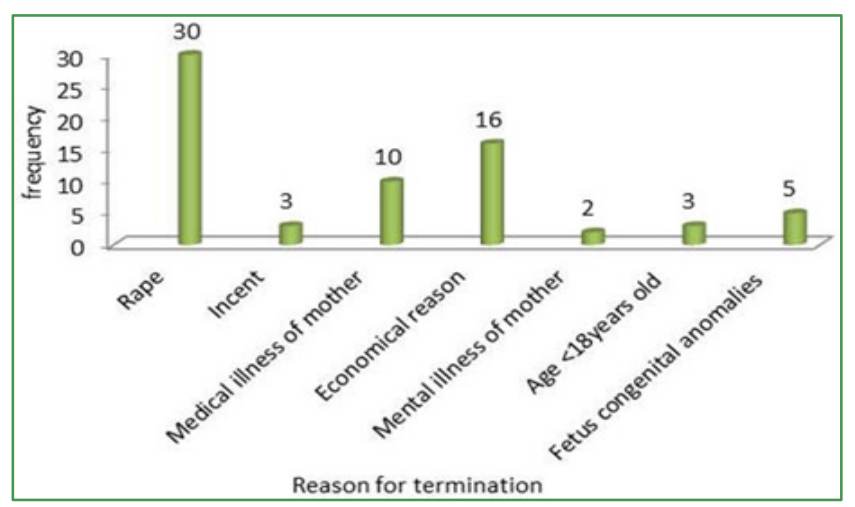

Figure 1. Frequency distribution of women with their reason for termination of pregnancy for safe abortion, from January2012-January2014 


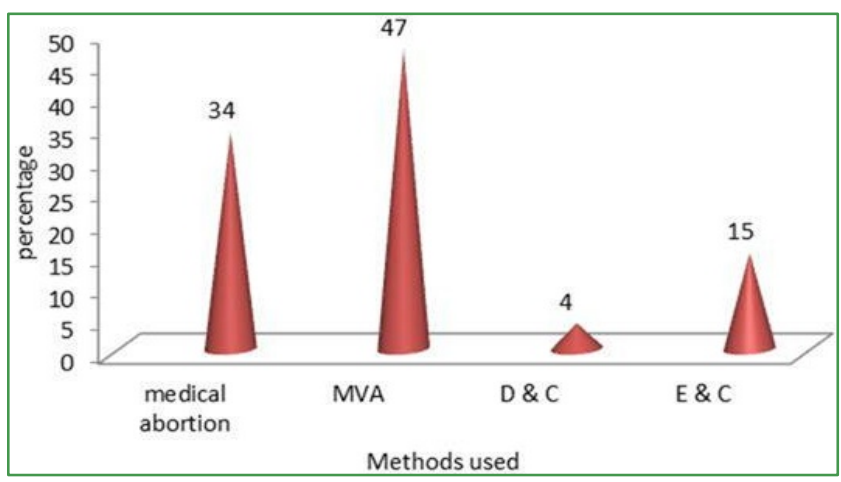

Figure 2. Percentage distribution of type of procedure done for induced abortion from January 2012-January 2014

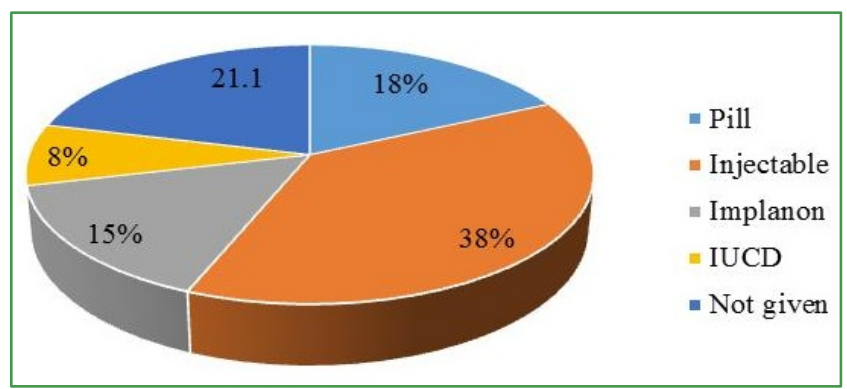

Figure 3. Percentage distribution of percentage of family planning used after abortion in JUSH South west Ethiopia from January 2012-2014

Table 1. The characteristics of respondents

\begin{tabular}{|c|c|c|c|}
\hline \multicolumn{2}{|c|}{ Variables } & Frequency & $\%$ \\
\hline \multirow{4}{*}{ Age in years } & $<19$ & 49 & 25.3 \\
\hline & $20-29$ & 85 & 43.8 \\
\hline & $30-39$ & 45 & 23.2 \\
\hline & $>40$ & 15 & 7.7 \\
\hline \multirow{3}{*}{ Marital status } & Single & 54 & 27.8 \\
\hline & Married & 130 & 67 \\
\hline & Widowed & 10 & 5.1 \\
\hline \multirow{6}{*}{ Occupation } & Student & 45 & 23.7 \\
\hline & House hold & 54 & 28.4 \\
\hline & Farmer & 28 & 14.4 \\
\hline & Merchant & 22 & 11.3 \\
\hline & Government employee & 38 & 19.6 \\
\hline & Others & 5 & 2.6 \\
\hline \multirow{2}{*}{ Residence } & Rural & 115 & 59.3 \\
\hline & Urban & 79 & 40.7 \\
\hline \multirow{4}{*}{ Gravity } & Premigravida & 54 & 27.8 \\
\hline & $2-5$ & 95 & 49 \\
\hline & $5-9$ & 37 & 19.1 \\
\hline & $\geq 10$ & 8 & 4.1 \\
\hline \multirow{4}{*}{ Parity } & 1 & 41 & 21.1 \\
\hline & $2-5$ & 73 & 37.6 \\
\hline & $5-9$ & 18 & 9.3 \\
\hline & $\geq 10$ & 3 & 1.5 \\
\hline \multirow{2}{*}{$\begin{array}{c}\text { Gestational } \\
\text { age by } \\
\text { trimester }\end{array}$} & $1^{\text {st }}$ trimester & 61 & 31.4 \\
\hline & $2^{\text {nd }}$ trimester & 133 & 68.6 \\
\hline
\end{tabular}

Table 2. Distribution of types of abortion and complications from January2012-January 2014

\begin{tabular}{|c|c|c|c|c|c|}
\hline \multirow{2}{*}{\multicolumn{2}{|c|}{ Variables }} & \multicolumn{2}{|c|}{ Septic } & \multicolumn{2}{c|}{ Aseptic } \\
\cline { 2 - 6 } & $\mathrm{N}$ & $\%$ & $\mathrm{~N}$ & $\%$ \\
\hline \multirow{4}{*}{$\begin{array}{c}\text { Spontaneous } \\
\text { abortion } \\
(\mathrm{N}=125)\end{array}$} & \begin{tabular}{c} 
Complete abortion (n=2) \\
\cline { 2 - 6 }
\end{tabular} & 2 & 1 & 0 & 0 \\
\cline { 2 - 6 } & $\begin{array}{c}\text { Incomplete } \\
\text { abortion(n=95) }\end{array}$ & 16 & 8.2 & 79 & 40.7 \\
\cline { 2 - 6 } & $\begin{array}{c}\text { Inevitable abortion(n } \\
=13)\end{array}$ & 2 & 1 & 11 & 5.7 \\
\cline { 2 - 6 } & Missed abortion (n=9) & 2 & 1 & 7 & 3.6 \\
\hline $\begin{array}{c}\text { Induced } \\
\text { abortion } \\
\text { (N=69) }\end{array}$ & $1^{\text {st }}$ trimester & 0 & 0 & 19 & 7.8 \\
\hline \multirow{2}{*}{ Total } & 2nd trimester & 1 & 0.5 & 49 & 25.3 \\
\hline
\end{tabular}

Table 3. Association of dependent and independent variables of the study at JUSH south west Ethiopia, from January 2012-January 2014

\begin{tabular}{|c|c|c|c|c|c|}
\hline \multicolumn{2}{|c|}{ Variables } & $\begin{array}{c}\text { Spontaneou } \\
\mathrm{s}\end{array}$ & $\begin{array}{c}\text { Induce } \\
\mathrm{d}\end{array}$ & $\mathrm{X}^{2}$ & p-value \\
\hline \multirow{5}{*}{$\begin{array}{c}\text { Occupatio } \\
n\end{array}$} & Student & 9 & 36 & \multirow{5}{*}{$\begin{array}{c}63.833 \\
8\end{array}$} & \multirow{5}{*}{$\begin{array}{c}\mathrm{P}=<0.00 \\
1\end{array}$} \\
\hline & Household & 49 & 6 & & \\
\hline & Farmer & 16 & 12 & & \\
\hline & Merchant & 17 & 5 & & \\
\hline & $\begin{array}{c}\text { Governme } \\
\text { nt } \\
\text { employee }\end{array}$ & 31 & 5 & & \\
\hline \multirow{2}{*}{ Residence } & Rural & 74 & 41 & \multirow{2}{*}{$90.0 \mathrm{E}$} & \multirow{2}{*}{$\begin{array}{c}\mathrm{P}=0.976 \\
2\end{array}$} \\
\hline & Urban & 51 & 28 & & \\
\hline \multirow{3}{*}{$\begin{array}{l}\text { Marital } \\
\text { status }\end{array}$} & Single & 9 & 45 & \multirow{3}{*}{$\begin{array}{c}93.066 \\
7\end{array}$} & \multirow{3}{*}{$\begin{array}{c}\mathrm{P}=<0.00 \\
1\end{array}$} \\
\hline & Married & 114 & 16 & & \\
\hline & Widowed & 2 & 8 & & \\
\hline \multirow{2}{*}{$\begin{array}{c}\text { Gestationa } \\
1 \text { age }\end{array}$} & $1^{\text {st }}$ TMP & 40 & 21 & \multirow{2}{*}{0.0505} & \multirow{2}{*}{$\begin{array}{c}\mathrm{P}=0.822 \\
1\end{array}$} \\
\hline & $2^{\text {nd }} T M P$ & 85 & 48 & & \\
\hline
\end{tabular}

\section{Result and Discussion}

According to this study, of the total calculated 194 sample size of the clients admitted for both spontaneous and induced abortion, 125(64.4\%) were spontaneous and 69(35.6\%) were induced abortion[Table 2]. 49(25\%) of the study participants were between 20-24years of age. 28(14.4\%) of incomplete abortion occurs between age of 25-29years. $155(59.3 \%)$ were from rural area 95(45\%) were multigravida) $130(67 \%)$ of them were married and $27.8 \%$ (54) were single while $55(28.4 \%)$ of them were household followed by student 46(23.7\%) and government employee 38 (19.6\%) more detail [Table 1].Occupation and marital status are strongly associated with types of abortion with $\mathrm{p}$-value of $\mathrm{P}<0.001$ According to this study $125(64.4 \%)$ were spontaneous and from 69(35.6\%) induced abortion 57 (82.6\%) happened under the age of 30 years while the rest $121(96.8 \%)$ of spontaneous abortion were common in age $<30$ years old. This is comparable with previous studies done in Gambella 
hospital showed that patients with induced abortion were younger, single and had a secondary education ${ }^{10}$. Conquering to this study in southwest Ethiopia showed that $81.5 \%$ of the induced abortions occurred among 15 to 25 years ${ }^{11}$. study in Wollega showed $36.4 \%$ were educate, $63.6 \%$ were uneducated, $22.4 \%$ were house wife, $89 \%$ are from rural, $10.9 \%$ were from urban ${ }^{12}$.Those married were comparable and those single where lower in this study which related to school based study at northern Ethiopia and those come from urban area is higher than and those from rural area is lower when compared to study in Wollega, because that study is more peripheral and Jimma is more urban and where the tertiary hospital and higher institution are available. The current finding is also in conformity with the finding in Tanzania, it was found that nearly a third of victims of unsafe abortion were teenagers of whom about one in every four were students of primary and secondary schools ${ }^{13}$.From $37(19.1 \%)$ of patients have had one or more abortion, $28(75.7 \%)$ had one to two abortion and $9(24.3 \%)$ had three and more abortion. When compared with a study done in Garage Zone, 207 (51.8\%) of the respondents have history of one or two pregnancies including the current pregnancy ${ }^{14}$. which is higher than the current study because of improving trend us of contraceptive, availability of health service at Jimma and number of pregnancy experienced is higher in rural than urban. Previous study done in Northwest Ethiopia ${ }^{15}$.shows the reasons given by the respondents for committing induced abortion are $31.3 \%$ due to fear of family and the community and $14.1 \%$ due to economic problem. The current study is also comparable with the study by S. Kebede at Jimma hospital revealed that the main reason for induced abortion was due to economic problem ${ }^{16}$. In the present study, rape $30(15.5 \%)$ and economic $16(8.2 \%)$ problem hold most indication of induced abortion.

In the current study, injectable and OCP had been utilized for post abortion family planning method accounting about $74(38.1 \%)$ and $35(18 \%)$ respectively which is higher than the Ethiopia DHS 20014 the contraceptive method used in all reproductive women's injectable (21.2\%) and pill account $(1.8 \%)$ respectively ${ }^{17}$ The difference may be DHS represent the wall country but the current study figured out only on Jimma University Teaching hospital. The most common clinical presentation in this study was vaginal bleeding $(63.4 \%)$, complaining termination of pregnancy $(35.6 \%)$ and about $1 \%$ were due to complications of pregnancy fever and pushing down pain respectively which is similar with reports of other studies ${ }^{18,19}$. The difference could be attributed to incomplete abortion and trauma to genital tract/uterus. The most common complication in this study was sepsis, $23(11.9 \%)$ It occurred in $57.1 \%$ of cases reported in Kaduna ${ }^{20}$ and $73 \%$ of cases in Niger Delta, Nigeria $^{21}$

\section{Limitation of the Study}

The main limitations of this study include its retrospective design, single-center site, the inability to calculate population-based mortality rates and this study didn't explore related complications management of each cases

\section{Conclusion and recommendation}

The study concludes that majority of abortion were spontaneous abortion which almost hold all septic abortion. Most of spontaneous abortion was incomplete followed by inevitable abortion. Incomplete septic $2^{\text {nd }}$ trimester pregnancy spontaneous abortion accounts most of septic abortion followed by incomplete $1^{\text {st }}$ trimester septic spontaneous abortion and majority of induced abortion were teenage, single students and most of them presented after $2^{\text {nd }}$ trimester of pregnancy which increases the complication of abortion. Rape is the most indication for termination of pregnancy in induced abortion thus health education on dangers of induced abortion, spontaneous abortion and utilization of contraceptive methods services to all women are highly recommended.

\section{Acronyms and Abbreviation \\ $1^{\text {st }}$ TMP: First Trimester Pregnancy \\ D\&C: Dilatation and Curettage \\ E\&C: Evacuation and Curettage \\ EDHS: Ethiopia demographic and health surveys \\ GTD: Gestational trophoblastic diseases \\ JUTH: Jimma University Teaching Hospital \\ MVA: Manual Vacuum Aspiration \\ OCP: Oral contraceptive pills}

\section{Conflicts of Interest}

The authors report no conflicts of interest in this work.

\section{Acknowledgements}

The author thanks Jimma university teaching hospital record office staffs for their invaluable cooperation during data collections.

\section{REFERENCES}

[1] Williams, obstetrics 23rdedition, page 216, 2010.

[2] Hitt J. Pro-life nation. http://www.nytimes.com/2006/04/09/ magazine/09abortion.html?ei=5070\&en=4eb39005afdd039a \&ex=115 2331200

[3] Okonfua FE, Odimegwu C, Ajabor H, Daru PH, Johnson A, assessing the prevalence and determinants of unwanted pregnancy and induced abortion in Nigeria, stud foam, plan 1999;30:67-77

[4] WHO, Induced abortion: incidence and trends worldwide Geneva, Switzerland; January, 19th, 


\section{DOI:10.1016/S0140-6736(11)61786-8}

[5] Elias Senbeto, GetuDeguAlene, NuruAbesno, HailuYenenehprevalence and assotiated factor of induced abortion in north west Ethiopia, Murch 2003

[6] Berer M. National laws and unsafe abortion: the parameters of change. Reprod Health Matters 2004; 12: 1-8

[7] Yosephsetal.A survey of illegal abortion in Addis Ababa Desember 1993, available at http://WWW. Reproductive rights, org (accessed July 26, 2008).

[8] KwastBE,RochalRW,Widadkidanmariam .maternal mortality in Addis Ababa Ethiopia. Study in family planning,1986,17(6):288-301

[9] TaddesseE.YosephS.Gossa A., Illegal abortion at five hospitals in Addis Ababa, Ethiopia .Med J.1994; 32:283-84.

[10] W/ Meskel Y and Chekol A. Induced abortion and prevalence of sexually transmitted infections and contraceptive behavior in abortion cases, Gambella Hospital. Ethiop. J. Health Dev. 1999; 9(2):77-83

[11] Desalegn M. Abortion as a social problem inJimma town, South West Ethiopia, Department of Sociology, Addis Ababa University, 1993.

[12] Fetene T. Teshome1 A. Gebremariam H. Aaderajew N. Teklehaymanot, Prevalence of unintended pregnancy and associated factors Ganji woreda, west Wollega Oromia region, Ethiopia 2014; 2(2): 92-101

[13] Silberschmidt M, Rasch V. Adolescent girls, illegal abortions and "sugar-daddies" in Dar es Salaam: Vulnerable victims and active social agents. Soc Sci Med 2001; 52:1815-26
[14] Tesfaye, Gezahegn, Mitiku Teshome Hambisa, and Agumasie Semahegn. 2014. "Induced Abortion and Associated Factors in Health Facilities of Guraghe Zone , Southern Ethiopia." 2014.

[15] Senbeto, Elias, Getu Degu Alene, Nuru Abesno, and Hailu Yeneneh. 2005. "Prevalence and Associated Risk Factors of Induced Abortion in Northwest Ethiopia." Ethiop.J.Health Dev. 19(1): 37-44.

[16] Kebede S, Jira C, and W/Mariam D. A Survey Of Illegal Abortion In Jimma Hospital South-Western, Ethiopia. Ethiopian Medical Journal. 2000;38 (1): 35-42

[17] Central Statistical Agency. Ethiopia demographic and health surveys (EDHS) Addis Ababa,Ethiopia: , Ethiopoa demographic and health surveys (DHS);2014

[18] Enabudoso EJ, Gharoro EP, Ande AB, Ekpe UP, Okohue EJ. Five year review of complicated induced abortions in University of Benin Teaching Hospital, Benin City. Benin J Postgrad Med 2007;9:13-21

[19] Ekanem EI, Etuk SJ, Ekabua JE, Iklaki C. Clinical presentation and complications in patients with unsafe abortions in University of Calabar Teaching Hospital, Calabar, Nigeria. Niger J Med 2009;18:370-4

[20] Adesiyun AG, Ameh C. An analysis of surgically managed cases of pelvic abscess complicating unsafe abortion. J Ayub Med Coll Abbottabad 2006; 18:14-6.

[21] Igberase GO, Ebeigbe PN. Exploring the pattern of complications of induced abortion in a rural mission tertiary hospital in the Niger Delta, Nigeria. Trop Doct 2008; 38:146-8. 